\title{
Posology in children oral liquid medication studies in Liberia
}

\author{
J. A. KOLAWOLE*, K.C. SMITH and P.D. PAYE \\ Department of Medicinal and Pharmaceutical Chemistry, School of Pharmacy, University of Liberia, Liberia. \\ *Corresponding author, E-mail:kolajac@yahoo.com
}

\begin{abstract}
The determination and implementation of appropriate dose(s) and dosing in children for effective therapeutic outcome devoid of medication errors is a concern to health practitioners and regulatory authorities. This study surveyed children oral medications on the Liberian pharmaceutical market for appropriate dose, dosing and delivery devices. In the qualitative work, caregivers were interviewed and surveys were conducted in pharmacies for oral medications and the quantitative phase involved the evaluation of the delivery devices. The result of the survey showed that $95.7 \%$ of caregivers followed instructions provided at the point of dispensing or as on label of product. Survey result showed that $56 \%$ of the oral medicinal products have specific direction for usage while $73 \%$ have the inscription "as directed by the physician", either alone or in combination with specific direction for use. Medicines with delivery device as cup were $80.94 \%$ and those with teaspoons were $1.79 \%$, while $17.28 \%$ do not have any form of delivery device. And $53.11 \%$ of the medicinal products provided instruction for delivery of the medicines in "teaspoonful", though they did not contain teaspoon neither were the cups graduated in "teaspoonful" format. Volume calibration of the various "5.0 ml" teaspoons showed statistically significant differences $(\mathrm{P}<0.05)$, while the cups volume capacities at $5.0 \mathrm{ml}$ was found to be $5.200 \pm 0.326 \mathrm{ml}$. The large volume cups showed significant differences $(\mathrm{P}<0.05)$ at the $5.0 \mathrm{ml}$ graduation and only $25.5 \%$ of the mothers were able to accurately measure out $5.0 \mathrm{ml}$ in the cups.

(C) 2015 International Formulae Group. All rights reserved.
\end{abstract}

Keywords: Medication error, posology, delivery devices, medical error, children oral medication.

\section{INTRODUCTION}

The use of medicines to mitigate ill health, promote or maintain health depends on the use of the right drug for the right condition and in the right dose and dosing (Gonzales, 2010; Sullivan and Buchino, 2004; Anderson and Holford, 2013; Gill et al., 2013). Dose and dosing in children has become a concern to medical practitioners and many regulatory authorities especially, in the USA, Europe and Britain, where guidelines has been developed for caregivers, and manufacturers (European
Parliament and Council of the European Union, 2006). Research reports have shown medical and medication errors to be a serious factor in medicine safety and therapeutic outcomes, including adverse drug reactions (Bond et al., 2001; Stucky, 2003; Gonzales, 2010). In a prospective cohort study, Kenneth et al. (2002) reported that $19 \%$ of the doses in children medications were in error, $17 \%$ were wrong dose/dosing and $43 \%$ were wrong timing. Also, Cella et al. (2010) reported that dosing recommendation in children must be 
derived from an integrated (model-based) analysis of pharmacokinetic and pharmacodynamic data, accounting for the role of disease factors as well as developmental growth. Moreover, optimal dosing in children ought to include an assessment of the impact of potential differences in mode of administration, pharmaceutical formulation and delivery devices. Therefore, to achieve the therapeutic response require, (pharmacodynamic or chemotherapeutic), the dose and formulation must be delivered by the right route and with the right delivery device (Johnson, 2005; Cetinkaya et al., 2010; Anderson and Holford, 2013; Gill et al., 2013).

In order to enhance excellent therapeutic outcome in children and to overcome medication errors, the USA-FDA, UK-MHRA (Medicines and Health products Regulation Authority) and European Parliament and Council, developed guidelines on dose and dosing for children medications generally and for some specific drugs like paracetamol (http://www.bpac.org.nz/BPJ/ 2010). The USA-FDA developed the "Guidance for Industry Dosage Delivery Devices for Orally Ingested OTC Liquid Drug Products". The opening statement in the guideline is "This document is intended to provide guidance to firms that are manufacturing, marketing, or distributing orally ingested over-the-counter (OTC) liquid drug products (e.g., elixirs, suspensions, solutions, syrups) that are packaged with dosage delivery devices (e.g., calibrated cups, droppers, syringes, spoons) Because; written, printed, or graphic matter appearing on dosage delivery devices packaged with OTC liquid drug products is considered LABELING and such markings on these devices must not be FALSE or MISLEADING and must be CLEAR and CONSISTENT with the drug product's directions for use". (Sections 201 the Federal (m), 502(a) and 502(£)(1) of Food, Drug, and Cosmetic Act.)
(http://www.fda.gov/cder/guidance/inde.Y.ht $\mathrm{m})$.

The FDA made some recommendations at the end of the document. "FDA's recommendations for orally ingested OTC liquid drug products are;

1. Dosage delivery devices should be included for all orally ingested OTC drug products that are liquid formulations;

2. These devices should have calibrated units of liquid measure marked on the device (e.g., teaspoon, tablespoon, or milliliter) that are the same as the units of liquid measure specified in the labeled dosage directions on any outside packaging (carton labeling), bottle, and any accompanying written instructions;

3. If units of liquid measure are abbreviated on the dosage delivery device, the abbreviation used on the device should be the same abbreviation used in the labeled dosage directions, outside packaging (carton labeling), bottle, and any accompanying written instructions;

4. Dosage delivery devices should not bear extraneous or unnecessary liquid measure markings that may be confusing;

5. Manufacturers should try to ensure that the dosage delivery devices are used only with the products with which they are included. Possible ways of accomplishing this are to either Include a statement on the drug product's bottle and/or carton labeling and, if possible, on the dosage delivery device that only the provided dosage delivery device is to be used with the particular OTC drug product with which it is included. The dosage delivery device included in the package must be consistent with the labeled dosage directions;

6. Dosage delivery devices should not be significantly larger than the largest dose described in the labeled dosage directions and should permit clear measurement and delivery of the smallest labeled dosage;

7. The liquid measure markings on dosage delivery devices should be clearly 
visible and not be obscured when the liquid product is added to the device;

8. The dosage delivery device for a drug product provides markings that can readily measure the dosage indicated by the directions on the bottle and/or carton labeling" (http://www.fda.gov/cder/guidance/inde.Y.ht $\mathrm{m})$.

Gonzales (2010) reported that although, the problem of medication error is a major concern, little is reported on it in the literatures. There are no specific regulations or policies on posology (dose and dosing) in children medications in Liberia nor any of the African countries, neither was there any study to establish the need for such regulation to our knowledge.

The aim of the study is to determine the level of compliance of manufacturers, caregivers and parents in the delivery of recommended dose(s) of medicines to children adopting the USA-FDA recommendations above as an evaluation tool.

\section{MATERIALS AND METHODS}

\section{Materials}

Teaspoons (plastic and metal types), graduated cups (10.0 to $30.0 \mathrm{ml}$ ) and children oral medications in their original containers were collected from the research sites. Micropipettes 0-1000 $\mu \mathrm{l}, 1-2500 \mu \mathrm{l}$ (USA) Volumetric flask $5 \mathrm{ml}, 10 \mathrm{ml}, 50 \mathrm{ml}$ (Pyrex, USA) Measuring cylinder $5 \mathrm{ml}, 10 \mathrm{ml}, 25 \mathrm{ml}$ (Pyrex, USA).

\section{Methods}

Qualitative and quantitative methods are employed for the study. The first phase was the qualitative work, where interviews and surveys were conducted and the second phase was the evaluation of the delivery devices.
First Phase

Review and survey of children medicinal products for delivery devices and labels (on packages or inserts)

A form was designed with the following components: name of product, type of medicine, volume of bottle, dose/dosage, direction for use/instruction for use, cup or teaspoon present and comment by investigator.

Four registered pharmacy outlets were chosen as research site. The criteria for choice were (i) pharmacies that are well stocked with children medications and (ii) location of the pharmacies. Two of the pharmacies were close to a major market (old road market) in Monrovia, one in the city centre - CareyJohnson street) while the other is the only pharmacy (5- 6 kilometer radius) close to the third largest hospital (Catholic Hospital, Congo Town).

Official approval was obtained from the shop owners for the survey. The survey at each site was carried out in one day. The survey was completed for the four premises in four days.

Each product was examined for the following; name, dose, direction for administration, presence of delivery device, size of delivery device, and any special directive.

\section{Prospective study on the use of delivery devises by mothers}

A cross sectional interview was conducted among volunteer nursing mothers. The mothers are either nursing children or done so in the last two years. Fifty of such women were interviewed using structured questionnaire. The site of survey was Congo Town community (by old road market area, VP road and catholic hospital junction) Monrovia. 


\section{Second Phase}

Two way calibrations of delivery devises (cups and teaspoons)

Calibration - through filling capacity

The facilitator measured $5.0 \mathrm{ml}$ of water and other oral liquid medicinal products with varying viscosity into each cup using previously calibrated $2500 \mu 1$ micro pipette. In the event of the water or the liquid not reaching the $5.0 \mathrm{ml}$ mark or passing the mark, the volume difference was determined using the $1000 \mu \mathrm{l}$ pipette. The volume (mean and standard deviation) for the cups were determined and subjected to statistical analysis using the student's T-Test.

Population calibration of cups

Delivery cups were collected from the pharmacies, medicinal product packs and from mothers. The cups were labeled and kept at room temperature. Volunteers, comprising of twenty (20) students of the School of Pharmacy were briefed on the protocol of the research. The volunteers were within the age range of 20 to 36 years old male and female students with good eye sights. Each student was requested to accurately measure $5.0 \mathrm{ml}$ of water using the cups. Each of the students randomly used 4-5 of the cups. The facilitator used the micropipettes to quantitatively remove the water and determine the volume. The average volume for each cup was determined and statistically compared with the expected volume of $5.0 \mathrm{ml}$ using the student's T-Test.

\section{Calibration of the teaspoons}

Teaspoons were collected from purchased medicine packs and mothers. The teaspoons were labeled and kept at room temperature. The spoon were filled to the brim (but not dripping) with water and the facilitator used the micropipettes to quantitatively remove the water and the volume determined. This process was repeated for glycerin, Amino-up gold syrup, Lymptocin (erythromycin) suspension and Feverlet (paracetamol syrup) oral solution.
The average volume for each teaspoon was determined and statistically compared with the expected volume of $5.0 \mathrm{ml}$ using the student's T-Test.

Calibration - through filling capacity of teaspoons

The facilitator measured $5 \mathrm{ml}$ of water and other liquid preparations with varying viscosity into each teaspoon. In event of the liquid not getting to the $5 \mathrm{ml}$ mark or where it is beyond it, the 1000 ul micropipette was used to adjust the volume till spoon is filled to the brim (but not dripping). The average was determined and subjected to student's T-Test.

\section{RESULTS}

Review and survey of children medicines for delivery devices and labels (on packages and inserts)

The analysis of the survey report is as on Table 1. A total of 108 children medicines were examined in the four (4) pharmacies used as site of research. The medicinal products are mostly syrups, solutions, elixirs $(63.98 \%)$ and suspensions $(36.02 \%)$. Children medicines with specific direction for usage either on the package or on the insert were $56 \%$ while a total of $73 \%$ have the inscription "as directed by the physician" on them either alone or in combination with specific direction for use. There are a total of $29 \%$ of such products which have both, specific instruction and the inscription "as directed by the physician".

Medicinal products with cup as delivery device accounted for $80.94 \%$ and those with teaspoons were $1.79 \%$, while $17.28 \%$ did not have any form of delivery device. Also $53.11 \%$ of the children medicines provided instruction for delivery of medicines with the words "teaspoonful" but they did not contain teaspoon nor did they have cups graduated in 'teaspoonful' unit. The volume capacities of the cups were approximately $10.0 \mathrm{ml}(64.89 \%)$ or above $10.0 \mathrm{ml}(35.11 \%)$ (Table 1$)$. 


\section{Review and survey of mothers' knowledge of medicines delivery devices and it's applications}

The survey targeted mothers who are currently nursing children or have recently (in the past two year) nursed a babe. A total of fifty 50 mothers were interviewed with a structured questionnaire however, three (3) could not adequately respond to the questions. A total of $95.7 \%$ of the mothers responded that, they follow instructions given by the physician, pharmacists, and nurses or at the point of dispensing and/or as appeared on the package of the medicine (Table 2). On their preference of delivery device, $11 \%$ of the mothers preferred teaspoons while $89 \%$ preferred cups. On testing their ability to use the cups, it was discovered that only $25.5 \%$ were able to accurately measure out $5.0 \mathrm{ml}$ in the cups provided, while $38 \%$ measured above the $5.0 \mathrm{ml}$ mark and $25.5 \%$ measured below, with about $11 \%$ not being able to use the cups or shy. Also, $72 \%$ of the mothers mixed two or more medicines in one cup for administration and $61.7 \%$ use one cup for more than one child (Table 2).

Evaluation of the volume capacity of teaspoons as delivery device

The result of the calibration of the various "teaspoons" using water and oral medicines dosage forms (solutions, suspension, elixir) of different viscosity are presented on Table 3. The teaspoons volume capacity ranged from 4.0 to $7.5 \mathrm{ml}$, with a Mean \pm SD of $5.389 \pm 1.219 \mathrm{ml}$. Statistical analysis of the volume capacities showed teaspoons with volume capacity of $4.0 \mathrm{ml}, 7.0$ $\mathrm{ml}$ and $7.5 \mathrm{ml}$ to differ significantly $(\mathrm{P}<0.05)$ from the collective mean $(5.389 \mathrm{ml})$ or the expected $5.0 \mathrm{ml}$ capacity. A latitudinal study where the same teaspoon is used for various dosage forms with varying degrees of viscosity and relative density showed statistically non-significant differences (Table 3).
Evaluation of the volume capacity of cups as delivery device

Twelve graduated cups of different shapes and sizes were collected. The shapes are mainly conical or cylindrical but the dimensions are so varied (Table 4). One of the cups (labeled C) has completely wrong graduations for the volume levels. The cup was graduated on two sides as such; 5.0 to $30.0 \mathrm{ml}$ on one side and 2.5 to $27.5 \mathrm{ml}$ on the other. The result, however, showed that the $5.0 \mathrm{ml} \mathrm{mark}$ is equivalent to $2.7 \mathrm{ml}$ volume and $10.0 \mathrm{ml}$ mark is equivalent to $6.0 \mathrm{ml}$ volume, while $20.0 \mathrm{ml}$ level was found to be $15.0 \mathrm{ml}$ volume.

Using the $5.0 \mathrm{ml}$ volume as surrogate for most medication dosing standard, therefore measuring volumes at the $5.0 \mathrm{ml}$ level, the volume capacities obtained ranged from 5.0 to $6.0 \mathrm{ml}$ (Mean $\pm \mathrm{SD} ; 5.200 \pm 0.326$ $\mathrm{ml})$. Two of the cups showed statistically significant difference $(\mathrm{P}<0.05)$ from the assumed volume of $5.0 \mathrm{ml}$ (Table 4).

Six (6) of the cups have extra space at the top of the cup, over and above the last volume marking. The mean circumferences of the open end of cups were $9.4 \mathrm{~cm}$ for $10 \mathrm{ml}$ cups (small mouth cup) and $12.9 \mathrm{~cm}$ for $30 \mathrm{ml}$ cups-(wide mouth cup).

\section{Population calibration (Evaluation of ease of use and accuracy of cup)}

The suitability of the twelve (12) cup samples was determined through population calibration. Table 4 showed the possible individual variations in filling the cups to 5.0 $\mathrm{ml}$ levels. The result showed that the filling of cups A, B, D, and L to the $5.0 \mathrm{ml}$ level by the twelve volunteers per group showed statistically significant differences ( $\mathrm{P}<0.05)$. The other seven cups, though vary marginally from the $5.0 \mathrm{ml}$ mark, the differences are not statistically significant $(\mathrm{P}>0.05)$. Cup $\mathrm{C}$ was wrongly graduated (as presented earlier). 
Table 1: Table showing the analysis of the survey of children oral medication in four pharmacies in Monrovia.

\begin{tabular}{llc}
\hline S/N & Indices & Mean of \% \\
\hline 1 & Total No. of medicines & $108(100 \%)$ \\
2a & Specific direction on use & 56 \\
2b & No specific direction except "As directed by physician" & 73 \\
2c & Both 2a and 2b above & 29 \\
3a & Cup present & 80.94 \\
3b & No Cup and No Spoon & 17.28 \\
3c & Spoon present & 1.79 \\
3d & No spoon present with direction of use in "teaspoonful” & 53.11 \\
3e & Type of cup - $\approx 10 \mathrm{ml}$ & 64.89 \\
3f & Type of cup - > 10 ml & 35.11 \\
4a & Suspension & 36.02 \\
4b & Solution/syrup/elixir & 63.98 \\
\hline
\end{tabular}

Table 2: Table showing the analysis of the survey of mothers in their application of delivery devices for children oral medication.

\begin{tabular}{lccc}
\hline Parameters evaluated in interview & Response & Count & \% Response \\
\hline Follow Instruction as given at dispensing & Yes & 45 & 95.7 \\
point/on pack & NR & 2 & 4.3 \\
\hline Preference of delivery device & Cup & 42 & 89 \\
& Spoon & 6 & 11 \\
\hline \multirow{3}{*}{ Ability to fill volume of cup accurately to } & Below & 18 & 38 \\
mark & Exact & 12 & 25.5 \\
& Above & 12 & 25.5 \\
& NR & 5 & 11 \\
\hline Use of Cup or Spoon for medicinal products & One drug only & 10 & 21 \\
administration & Mixed all drugs & 34 & 72 \\
& NR & 3 & 7 \\
\hline \multirow{3}{*}{ After administration of drugs } & Wash off & 20 & 42.6 \\
& Wash before & 18 & 38.3 \\
& administering next & & \\
& NR & 8 & 17.1 \\
\hline \multirow{2}{*}{ Use of cup for other children } & Yes & 29 & 61.7 \\
& No & 7 & 15 \\
\hline NR No & NR & 11 & 23.3 \\
\hline
\end{tabular}


Table 3: Table showing the calibration of the nine different types of " $5 \mathrm{ml}$ teaspoons" using water and oral medicines dosage forms (solutions, suspension, elixir) of different viscosity.

\begin{tabular}{|c|c|c|c|c|c|c|}
\hline $\begin{array}{ll}\text { Code } & \text { of } \\
\text { teaspoons } & \end{array}$ & $\begin{array}{c}\text { Water as } \\
\text { universal } \\
\text { solvent }\end{array}$ & $\begin{array}{l}\text { Solution (Feverlet } \\
\text { syrup- paracetamol } \\
\text { oral Solution) wt/ml } \\
\quad=1.1228\end{array}$ & $\begin{array}{c}\text { Suspension } \\
\text { Lymphocin } \\
\text { (erythromycin } \\
\text { Suspension) } \\
\text { wt } / \mathbf{m l}=1.1120\end{array}$ & $\begin{array}{c}\text { Amino-Up Gold } \\
\text { (multivitamine } \\
\text { elixir) } \mathrm{wt} / \mathrm{ml}= \\
1.2280\end{array}$ & $\begin{array}{c}\text { Glycrine BDH (As } \\
\text { control in viscosity) } \\
w t / m l=1.257-1.261\end{array}$ & T-test result \\
\hline $\mathbf{A}$ & $4.00^{*}$ & 4.00 & 4.00 & 4.00 & 4.00 & $\mathrm{P}>0.05$ \\
\hline B & $4.00 *$ & 4.00 & 4.00 & 4.00 & 4.00 & $\mathrm{P}>0.05$ \\
\hline C & 5.00 & 6.00 & 5.00 & 5.00 & 5.00 & $\mathrm{P}>0.05$ \\
\hline D & 5.00 & 7.00 & 7.00 & 7.00 & 6.00 & $\mathrm{P}>0.05$ \\
\hline $\mathbf{E}$ & $6 \mathrm{ml}$ & 5.00 & 5.00 & 5.00 & 6.00 & $P>0.05$ \\
\hline $\mathbf{F}$ & $7.00 *$ & 7.00 & 7.00 & 7.00 & 6.50 & $\mathrm{P}>0.05$ \\
\hline $\mathbf{G}$ & $7.50 *$ & 7.50 & 7.50 & 7.50 & 6.50 & $P>0.05$ \\
\hline I & 5.00 & 5.00 & 5.00 & 5.00 & 5.00 & $P>0.05$ \\
\hline 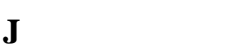 & 5.00 & 5.00 & 5.00 & 5.00 & 5.00 & $P>0.05$ \\
\hline
\end{tabular}


J. A. KOLAWOLE et al. / Int. J. Biol. Chem. Sci. 9(1): 176-185, 2015

Table 4: Showing parameters (dimensions/graduations) of cups and calibration results of ture volume capacities and population calibration ( $\mathrm{n}=12$ ).

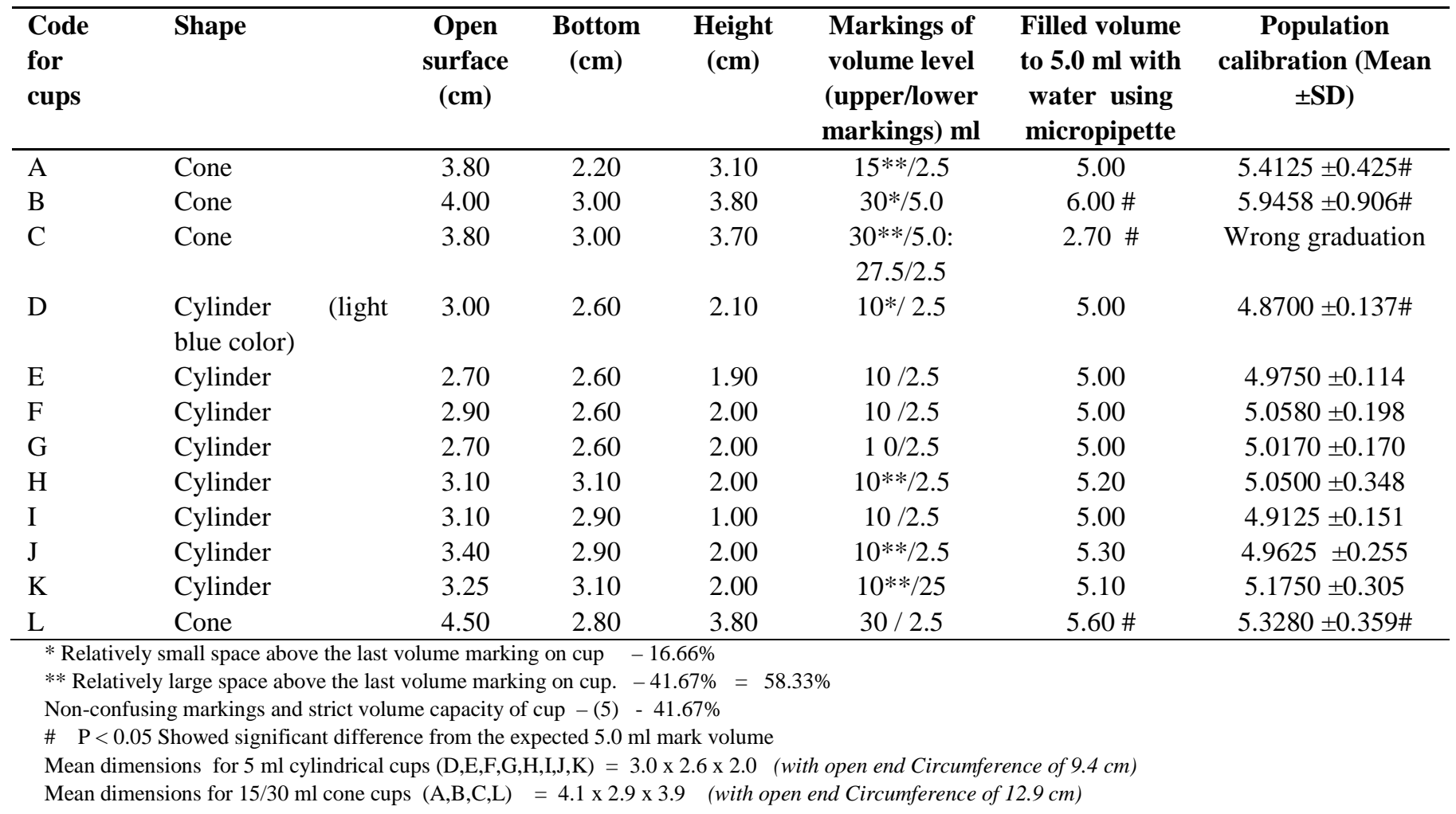




\section{DISCUSSION}

The study evaluated both the producers of children oral medicinal products and caregivers with respect to recommended dose(s), dosing regimen and presence/application of delivery devices. The survey showed that $95.7 \%$ of mothers follow instructions on the packaged and/or the ones given at the point of dispensing of drug (Table 2 ). With this as baseline, it becomes necessary for instructions to be clear and unambiguous. The result of the survey of dose/dosing instructions showed that $73 \%$ for the medicinal products used the phrase "as directed by physician", with no specific direction for the caregivers to use. This might lead to medication error. This corroborates previous reports that the possibility of medication error arises if the right dose is not complimented with the right dosing (Sullivan and Buchino 2004; Gonzales 2010; Anderson and Holford 2013; Gill et al., 2013).

The result of the knowledge of the mothers in using delivery devices showed that $11 \%$ preferred teaspoon while $89 \%$ preferred the cups. The survey of availability of delivery devices and types showed that $80.94 \%$ of the medicines come with cup and only $1.79 \%$ comes with teaspoon, while $17.28 \%$ do not have any form of delivery device, though the USA-FDA guideline require that delivery device must accompany product. It will therefore imply that such mothers with preference for teaspoon may use any available teaspoon or cup. This will most likely lead to medication error since the evaluation result of the teaspoons showed statistically significant differences $(\mathrm{P}<0.05)$ in volume capacity, with volumes ranging from $4.0 \mathrm{ml}$ to $7.5 \mathrm{ml}$ (Table 3 ).

While $80.94 \%$ of the manufacturers provided graduated cups with their products and $89 \%$ of mothers preferred the use of such cups, the study showed that only $25.5 \%$ were able to use the cups accurately by instructions of measuring $5.0 \mathrm{ml}$ volume. Further to this finding, a population calibration of the collected cups were carried out and the result (Table 4) showed that the cups (A, B. D, L) with wide mouth and large volumes (volumes above $10.0 \mathrm{ml}$ ) are highly subject to measuring errors as the result showed statistically significant difference $(\mathrm{P}<0.05)$. Also, the cups have total volume capacity that is significantly larger than the largest dose, therefore these cups are inconsistent with the USA-FDA recommendation No 4 and 6) The cups that are about $10.0 \mathrm{ml}$ did not show statistically significant difference in measuring volume. One of the graduated cups (Cup C) was found to be incorrectly or falsely graduated (Table 4). This is inconsistent with the USA-FDA recommendations (recommendation No 2,3,4 and 8 in introduction above). This cup delivers about half of the intended dose. Also, there are graduation on both sides of the cup which gave conflicting volume capacity (such as $10.0 \mathrm{ml}$ on one side and the other side was 7.5 $\mathrm{ml}$ and the real measured volume was $6.0 \mathrm{ml}$ ) While no mother noticed this erroneous label on cup, about $50 \%$ of the volunteers in the population calibration exercised noticed it. This is a direct source of medication error leading to administration of sub therapeutic doses.

All the cups provided with the medicines were graduated in milliliters while all the instructions were either "teaspoonful" or teaspoonful and in milliliters. A total of $53 \%$ of the medicines did not have spoon in the package but gave the instruction of use in teaspoon. This type of instruction leads to error in dosing (Wong et al., 2009). This also contradicts the USA-FDA recommendation No 2, which require that devices should be calibrated in units of liquid measure marked on the device that are the same as the unit of liquid measure specified on the label.

\section{Conclusion}

For the safety of children and to achieve the desired therapeutic outcome, it is pertinent for regulatory authorities to regulate the products' dose/dosing as well as its delivery devices in addition to routine regulatory parameters employed during registration of products. Using the FDA's recommendation for orally ingested OTC liquid drug products as evaluation tool, it can be concluded that the manufacturers complied by providing dose(s) on labels (inserts or on the package), but did not comply with the unambiguity requirement of the dosing 
regimen by the FDA guideline which require that label should be clear, not misleading and not false. The ambiguity may lead to individual interpretation of dosing of medications as earlier observed and reported by Kozer (2009). All the cups provided were not graduated in units consistent with the direction for use as recommended by the USA-FDA guideline. The teaspoons were not equivalent in capacity $(5.0 \mathrm{ml})$ as assumed therefore they are potential sources of medication error. The cups with capacities of $\leq 10 \mathrm{ml}$ were found to be more efficient in drug delivery than those of capacities $\geq 10.0$ $\mathrm{ml}$. The size and shape of the cups influence their efficiency in delivery. In view of the findings, there is the need for Liberia and other African countries to develop guidelines on oral medications in children.

\section{ACKNOWLEDGMENTS}

Authors would like to thank all volunteers, mothers, $2^{\text {nd }}$ year students for their cooperation and participation in the work.

\section{REFERENCES}

Anderson BJ, Holford NHG. 2013. Understanding dosing: children are small adults, neonates are immature children. Arch. Dis. Child., 98(9): 737-744.

Bond CA, Raehl CL, Franke T. 2001. Medication errors in United States hospitals. Pharmacotherapy., 21(9): 1023-1036.

Cella M, Catherijne K, Meindert D, Oscar DP. 2010. What is the right dose for children? Br. J. Clin. Pharmacol., 70(4): 597-603.
Çetinkaya Ş, Karataş Y, Antmen AB, Alhan E. 2010. Knowledge and behavior of the pediatricians on rational use of antibiotics. Afr. J. Pharm. Pharmaco., 4(11): 783-792.

European Parliament and Council of the European Union. 2006. Regulation (EC) No. 1901/2006 on medicinal products for paediatric use. (12 December 2006).

Gill A, Davey C, Kettle N, Morecroft C, Aider H. 2013. Parental understanding of dosing instruction for paracetamol and ibuprofen suspension. Arch. Dis. Child., 98: e13.

Gonzales K. 2010. Medication administration errors and the pediatric population: a systematic search of the literature. $J$. Pediatr. Nurs., 25(6): 555-565.

Johnson TN. 2005. Modelling approaches to dose estimation in children. Br. J. Clin. Pharmacol., 59: 663-669.

Kenneth NB, Flynn EA, Gnette APDavid WBMaekel RL. 2002. Medication errors observed in 36 health facilities. Arch. Intern. Med., 162: 1897 -1903.

Kozer E. 2009. Medication Errors in Children. Pediatric Drugs., 11(1): 52-54.

Stucky ER. 2003. American Academy of Pediatrics Committee on Drugs, American Academy of Pediatrics Committee on Hospital Care. Prevention of medication errors in the pediatric inpatient setting. Pediatrics., 112(2): 431-436.

Sullivan JE, Buchino JJ. 2004. Medication errors in pediatrics: The octopus evading defeat. J. Surg. Oncol., 88 (3): 182-188.

Wong I, Wong L Cranswick N. 2009. Minimizing medication errors in children. Arch. Dis. Child., 94: 161-164. 